\title{
Comparison of Axial Ocular Measurements with Contact and Non-Contact Biometry
}

\author{
Muhammad Arslan Ashraf ${ }^{1}$, Muhammad Suhail Sarwar ${ }^{2}$, Muhammad Awais Afzal ${ }^{3}$ \\ Imran Khalid ${ }^{4}$, Sehrish Shahid ${ }^{5}$ \\ ${ }^{1,2,5}$ Department of Ophthalmology, KEMU. ${ }^{3}$ Lahore General Hospital, ${ }^{4}$ Services Hospital, Lahore
}

\begin{abstract}
Purpose: To compare between non-contact and contact biometry for measurements of central corneal thickness (CCT), anterior chamber depth (ACD), lens thickness (LT) and axial length (AL).

Study Design: Descriptive Cross Sectional Study.

Place and Duration of Study: Mayo Hospital, Lahore from June 2018 to December 2018.

Material and Methods: Eighty-four subjects, (168 non-pathological eyes) visiting the eye outpatient's department were recruited by non-probability convenience sampling. Patients with high refractive errors and suffering from any ocular pathology were excluded from the study. CCT, ACD, LT and AL were measured with non-contact Biometer (HAAG Streit) followed by Contact Biometer (Ultrasound) after taking consent from the patient. Data was entered and analyzed by using SPSS-21 and Medcalc software. Normality of quantitative data was checked with Shapiro Wilk test. Independent sample t test was used for parametric variable and Mann Whitney-U test was used for non-parametric data. For the agreement between two techniques Cohen's Kappa test used and Bland-Altman plot was drawn for graphical presentation. p-value equal or less than 0.05 was taken as significant.
\end{abstract}

Results: Mean age of 84 subject (female: $45.24 \%$ and male: $54.76 \%$ ) was $53.05 \pm 13.56$ years. The AL was significantly longer for the non-contact measurement with the difference of $0.53 \pm 0.32 \mathrm{~mm}(p<0.001)$. Contact pachymetry was significantly higher with the difference of $8.67 \pm 20.83 \mu \mathrm{m}(p=0.046)$. ACD was significantly deeper for non-contact measurements with the difference of $0.51 \pm 0.32 \mathrm{~mm}(p<0.001)$. Contact ultrasound Ascan measured LT significantly thicker with the difference of $0.59 \pm 0.56 \mathrm{~mm}(p<0.001)$.

Conclusion: There is significant difference of axial ocular measurements (CCT, ACD, LT and AL) between contact (ultrasound A-scan) and non-contact (HAAG Streit) biometry $(p<0.05)$.

Keywords: Biometry, Cataract, Axial Length, Anterior Chamber Depth, Central Corneal Thickness.

How to Cite this Article: Ashraf MA, Sarwar MS, Afzal MA, Khalid I, Shahid S. Comparison of Axial Ocular Measurements with Contact and Non-Contact Biometry, Pak J Ophthalmol. 2020; 36 (1): 72-78.

DOI: https://doi.org/10.36351/pjo.v36i1.922.

\section{INTRODUCTION}

It has been proven that ocular optics is working on the basis of refractive parameter of eyeball structure, which changes with age. Continuous flattening of anterior chamber (AC) and ocular crystalline lens

Correspondence to: Muhammad Arslan Ashraf

BS Vision Sciences,

Email: rajkumararslan@yahoo.com thickening is the best example of such structural changes with increasing age. ${ }^{1}$ In current century, advances in cataract surgery techniques have made ocular biometry more and more important. Instead of advancement in cataract surgery techniques, the accuracy is still dependent on precise biometry technique. The patients going for cataract surgery have high expectations of visual results and expect a spectacle-free life. This patient's expectancy of good 
visual quality after cataract surgery depends upon accurate measurement of keratometry (K-reading), anterior chamber depth (ACD), lens thickness (LT) and axial length (AL) $)^{2-5}$. Biometry can be classified as (a) contact and (b) non-contact ${ }^{6,7}$. It is found that the $1 \mathrm{~mm}$ measurement error in $\mathrm{AL}$, corneal radius and $\mathrm{ACD}$ can induce $2.7 \mathrm{D}, 5.7 \mathrm{D}$ and $1.5 \mathrm{D}$ of refractive error, respectively.

Noncontact biometry devices use the principle of Partial Coherence Interferometry (PCI). However, the ultrasound technique requires physical direct or indirect (immersion technique) contact of transducer with the cornea. Both ultrasound (US) A-scan biometry and non-contact PCI based devices are used for calculating IOL power ${ }^{6,8}$. AL in ultrasound method is measured from corneal vertex to the internal limiting membrane (ILM) ${ }^{9}$. The ultrasound biometry can be performed by applanation of the probe to the corneal surface or by indirectly contact of probe to corneal surface in immersion technique (by using saline filled shell). Due to saline filled shell, in immersion A-scan technique the chance of corneal indentation is negligible as a result the AL length measured in immersion technique is longer as compared to direct contact A-scan method. The PCI non-contact device simultaneously measures AL, ACD, LT and keratometry reading. All these factors play important role for IOL calculation. The PCI uses laser diode in the near infrared spectrum of $780 \mathrm{~nm}$ for measuring $\mathrm{AL}$ and other parameters ${ }^{10,11}$. Non-contact Biometer calculates the AL as distance between corneal epithelium to retinal pigment epithelium (RPE). Another advantage of non-contact Biometer over ultrasound contact method is to provide different IOL power formulas for single IOL model, however, it is unable to measure biometric parameters in dense cataract $^{12}$. Therefore, in all cases ultrasound biometry cannot be replaced by non-contact biometry ${ }^{9,13}$. A recent study on comparison between contact and noncontact biometry reported that both techniques were comparable with no clinical significant difference in measuring $\mathrm{AL}^{13}$.

We compared biometric parameters to find difference between ultrasound biometry and noncontact HAAG Streit Biometer.

\section{MATERIAL AND METHODS}

This study was done at Mayo Hospital, Lahore. It was a cross-sectional study done on 168 non-pathological eyes of 84 subjects. Participants of the study were selected by non-probability convenience sampling. Patients with high refractive errors ( \pm 4 Diopters) were excluded. Axial ocular measurements CCT, ACD, LT and AL were measured with non-contact Biometer (HAAG Streit) followed by Contact Biometer (Ultrasound) after instilling Alcaine eye drops as local anesthesia.

Data was entered and analyzed by using SPSS-21 and Medcalc software. Normality of quantitative data was checked with Shapiro Wilk test. Variables having $p$ value $\geq 0.05$ was considered as normally distributed. Independent sample $t$ test was used for parametric variable and Mann Whitney-U test was used for nonparametric data. For the agreement between two techniques, Cohen's Kappa test was used and BlandAltman plot was drawn for graphical presentation. Bland-Altman plots are graphs of the differences between the readings measured with the two methods plotted on the $y$-axis against the mean for the pairs of measurements plotted on the $\mathrm{x}$-axis. $\mathrm{p}$-value equal to or less than 0.05 was taken as significant.

Before examination, written consent was taken from all participants after giving detailed description of methodology of the study. The study was reviewed and approved by ethical committee of King Edward Medical University, Lahore.

\section{RESULTS}

We examined 168 eyes of 84-subjects. Out of 84 subjects $38(45.24 \%)$ were female and $46(54.76 \%)$ were male. Mean age of the female participants was $49.92 \pm 12.81$ years and mean age of male participants was $55.63 \pm 13.75$ years. Mean age of 84 participants recorded was $53.05 \pm 13.56$ years (Table 1 ).

Table 1: Age Distribution.

\begin{tabular}{|c|c|c|c|}
\hline \multicolumn{4}{|c|}{ Descriptive Statistics of Age } \\
\hline & Female & Male & Total \\
\hline $\mathrm{N}(\%)$ & $38(45.24 \%)$ & $46(54.76 \%)$ & 84 \\
\hline Minimum & 25.0 & 21.0 & 21.0 \\
\hline Maximum & 70.0 & 80.0 & 80.0 \\
\hline Mean & 49.921 & 55.630 & 53.048 \\
\hline Std. Deviation & 12.8071 & 13.7507 & 13.5575 \\
\hline
\end{tabular}

Comparison between CCT measured with noncontact and ultrasound technique showed that there was statistically significant difference $(p<0.046)$. The CCT was lesser in non-contact Biometer (Table 2). 
Comparison of ACD also showed that there was statistically significant difference $(\mathrm{p}<0.001)$. The ACD was deeper in non-contact Biometer. The difference between both techniques was $0.51 \pm$ $0.32 \mathrm{~mm}$. LT was thinner in non-contact Biometer as compared to contact Biometer (ultrasound). The difference between both techniques was $0.59 \pm$ $0.56 \mathrm{~mm}$ (Table 2). The comparison of AL also showed a statistically significant difference between non- contact and ultrasound technique $(\mathrm{p}<0.05)$. AL was larger in non-contact Biometer as compared to contact Biometer (ultrasound). The kappa value showed that there is poor agreement between both techniques as it is less than 0.20 (Table 2). The kappa value showed that there was poor agreement in measuring axial ocular measurements with both techniques, as it is less than 0.20 (Fig. 1).

Table 2: Statistical comparison of CCT, AL, ACD and LT measured with non-contact (HAAG Streit) and contact (ultrasound) technique.

\begin{tabular}{|c|c|c|c|c|c|c|c|c|c|}
\hline & Technique & Minimum & Maximum & Mean & $\begin{array}{l}\text { Std. } \\
\text { Error }\end{array}$ & $\begin{array}{c}\text { Std. } \\
\text { Deviation }\end{array}$ & $\begin{array}{l}\text { Mean } \\
\text { Diff. }\end{array}$ & $\begin{array}{c}\text { Mean Diff. } \\
\text { Std. Deviation }\end{array}$ & P-Value \\
\hline Central & Non-Contact & 461 & 610 & 521.625 & 2.4645 & 31.943 & \multirow[b]{2}{*}{-8.67} & \multirow[b]{2}{*}{20.83} & \multirow[b]{2}{*}{0.046} \\
\hline $\begin{array}{l}\text { Corneal } \\
\text { Thickness }\end{array}$ & Ultrasound & 450 & 648 & 530.292 & 2.9168 & 37.8061 & & & \\
\hline Axial & Non-Contact & 21.15 & 25.48 & 23.3139 & 0.06773 & 0.87784 & \multirow{2}{*}{0.53} & \multirow{2}{*}{0.32} & \multirow{3}{*}{$<0.001$} \\
\hline Length & Ultrasound & 20.44 & 25.26 & 22.7855 & 0.07121 & 0.92295 & & & \\
\hline Anterior & Non-Contact & 2.24 & 4.14 & 3.1786 & 0.03291 & 0.42656 & \multirow[b]{2}{*}{0.51} & \multirow[b]{2}{*}{0.32} & \\
\hline $\begin{array}{l}\text { Chamber } \\
\text { Depth }\end{array}$ & Ultrasound & 2.17 & 3.77 & 2.6718 & 0.02511 & 0.32544 & & & $<0.001$ \\
\hline $\begin{array}{l}\text { Lens } \\
\text { Thickness }\end{array}$ & $\begin{array}{l}\text { Non-Contact } \\
\text { Ultrasound }\end{array}$ & $\begin{array}{l}2.59 \\
1.85\end{array}$ & $\begin{array}{l}5.6 \\
5.95\end{array}$ & $\begin{array}{l}4.2643 \\
4.8537\end{array}$ & $\begin{array}{l}0.03719 \\
0.04924\end{array}$ & $\begin{array}{l}0.48204 \\
0.63824\end{array}$ & -0.59 & 0.56 & $<0.001$ \\
\hline
\end{tabular}

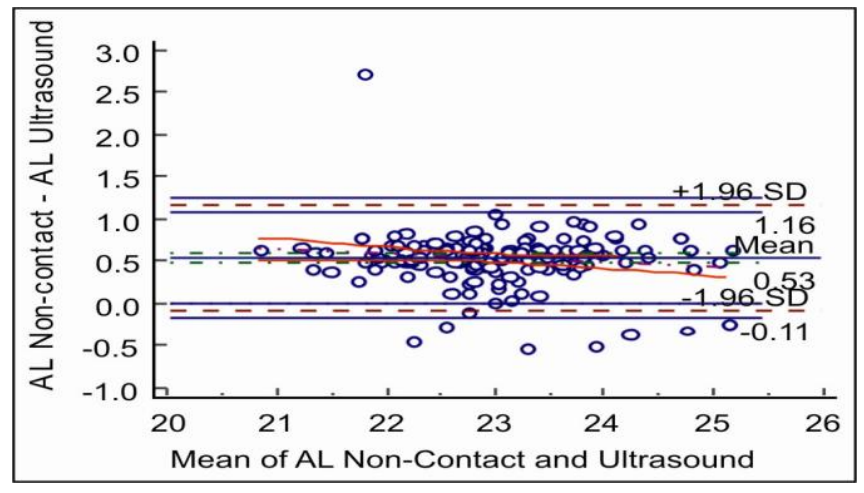

Fig. 1a: Bland-Altman plot for CCT comparing US with non-contact biometry. -49.5 to $32.2 \mu \mathrm{m}$ was the $95 \%$ limit of agreement $\left(R^{2:} 0.08633\right)$.

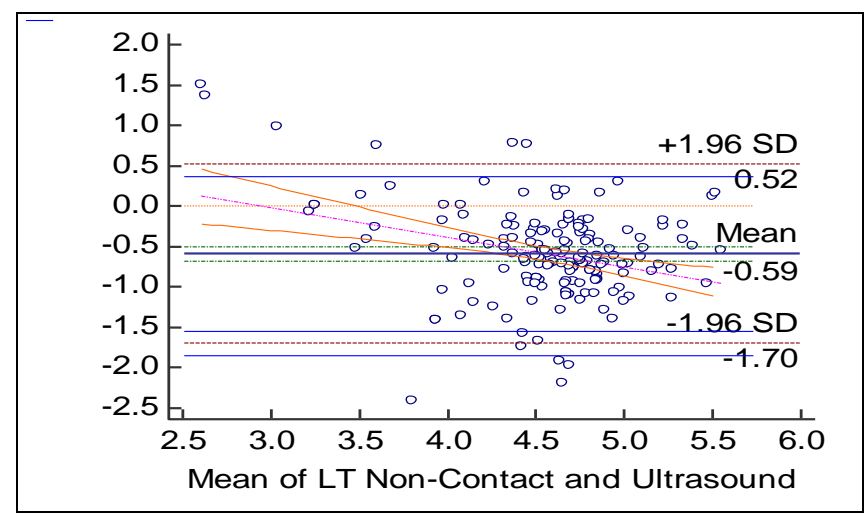

Fig. 1b: Bland-Altman plot for AL comparing US with non-contact biometry. -0.11 to $1.16 \mathrm{~mm}$ was the $95 \%$ limit of agreement $\left(R^{2:} 0.01992\right)$.

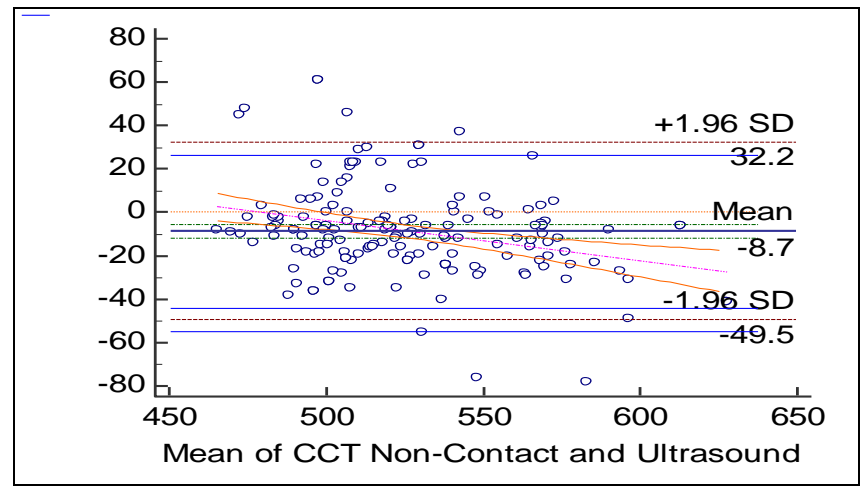

Fig. 1c: Bland-Altman plot for LT comparing US with non-contact biometry. -1.70 to $0.52 \mathrm{~mm}$ was the $95 \%$ limit of agreement (R2: 0.09983).

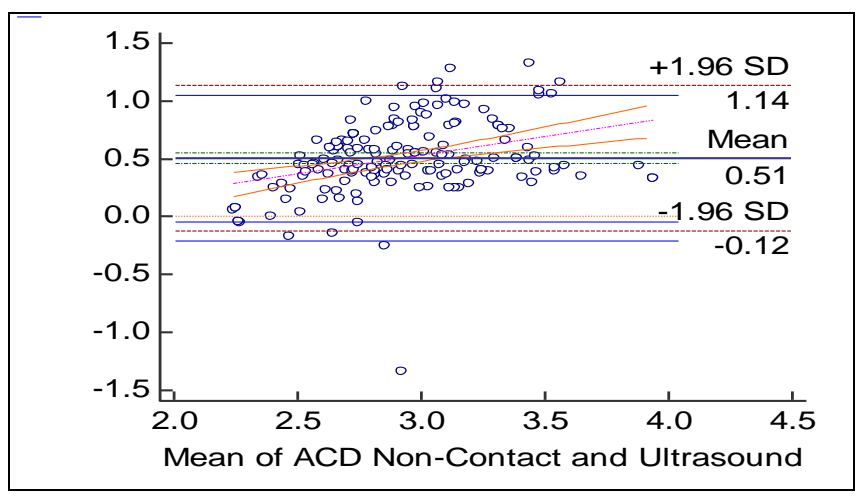

Fig. 1d: Bland-Altman plot for ACD comparing US with non-contact biometry. -0.12 to $1.14 \mathrm{~mm}$ was the $95 \%$ limit of agreement (R2: 0.1183). 


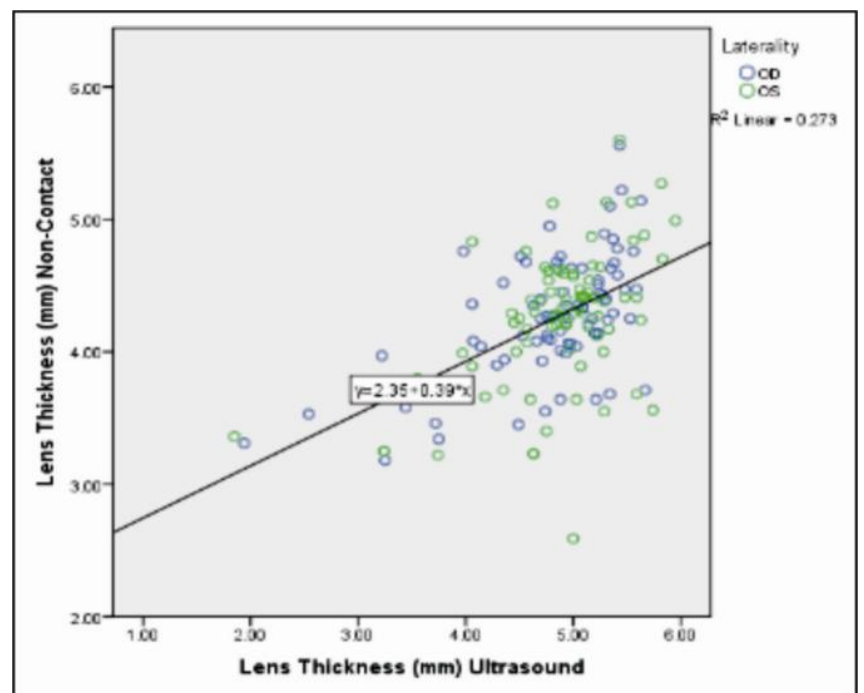

Fig. 2a: LT contact vs. non-contact.

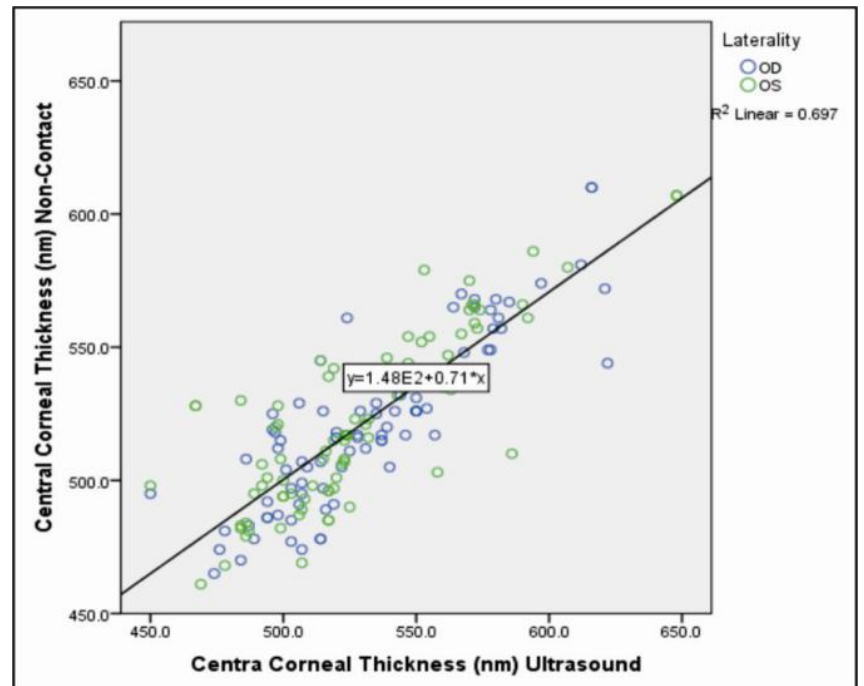

Fig. 2b: CCT contact vs. non-contact.

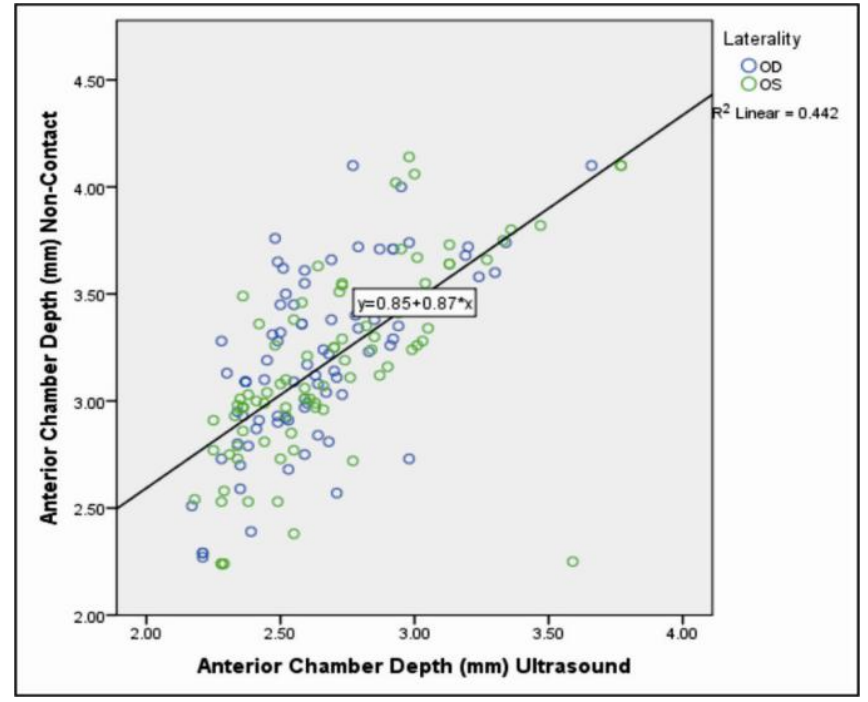

Fig. 2c: $A C D$ contact vs. non-contact.

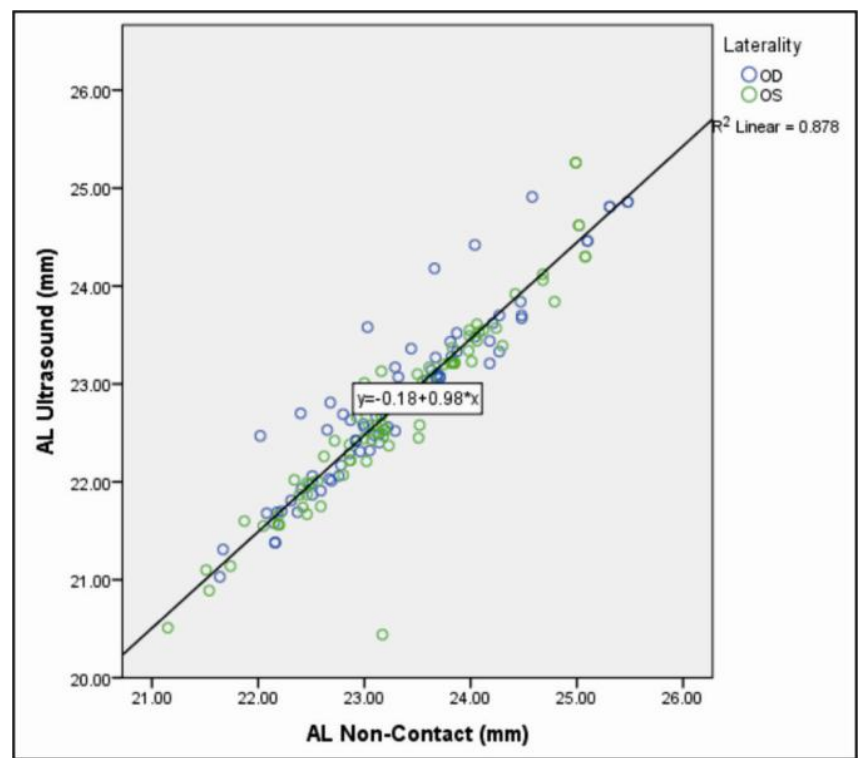

Fig. 2d: AL contact vs. non-contact.

There was also strong correlation found between axial parameters as CCT increases with deepening of ACD. Likewise, ACD and CCT had negative correlation but strong positive relationship with ACD.

\section{DISCUSSION}

Partial Coherence Interferometry (PCI) is a noncontact biometry technique, which provides dexterity in measuring K-reading, CCT, ACD, LT and AL in a single sitting. This is the main advantage of noncontact PCI Biometer when compared with conventional ultrasound Biometer. One more disadvantage of ultrasound biometry is that it is time consuming and requires topical anesthesia for corneal applanation. Further, the precision achieved with partial coherence laser interferometry was shown to be 10 times better than that of ultrasound in earlier studies $^{14}$.

This study found significant difference between non-contact and ultrasound technique with the bias of $8.67 \pm 20.83 \mu \mathrm{m}(\mathrm{p}=0.046)$. The mean CCT was $521.63 \pm 31.943 \mu \mathrm{m}$ and $530.29 \pm 37.806 \mu \mathrm{m}$ measured with non-contact and ultrasound technique, respectively. In contrast to previous studies, in which CCT with noncontact Biometer was always less than the corresponding US Biometer of up to $36 \mu \mathrm{m}$, the mean difference in our study was $8.67 \mu \mathrm{m}(95 \%$ confidence interval [95\% CI] -49.5 to 32.2 ). Suzanna Airiani et al, also found that CCT with noncontact appeared to measure slightly smaller than US. ${ }^{15}$ 
Christoph Tappeiner et al, found that the mean CCT with noncontact and ultrasound technique was $549 \pm$ $36.4 \mu \mathrm{m}$ and $545 \pm 38.2 \mu \mathrm{m}$ respectively with the difference of $-3.60 \mu \mathrm{m}(\mathrm{p}=0.005)$. Slight indentation by the examiner may alter the measurement of CCT with ultrasound biometry ${ }^{16}$. Sallet $\mathrm{G}$ et al. also found that the non-contact Biometer measured less CCT as compared to contact ultrasound technique ${ }^{17}$. Much and Haigis compared CCT measurements in 104 eyes with 4 pachymeters (3: PCI Biometers; 1: ultrasound Biometer). Ultrasound pachymeter was used as the gold standard. The researcher found that the difference between PCI and ultrasound Biometer was statistically significant. The difference was $<10 \mu \mathrm{m}$, the agreement was good and the results can be regarded as clinically interchangeable ${ }^{18}$.

In the comparison of anterior chamber depth, the mean ACD found was $3.18 \pm 0.43 \mathrm{~mm}$ and $2.67 \pm$ $0.33 \mathrm{~mm}$ measured with non-contact and ultrasound technique, respectively. The difference between both techniques was $0.51 \pm 0.32 \mathrm{~mm}(\mathrm{p}<0.001)$. Another study showed that the results of ACD measurements with several noncontact instruments can differ greatly $^{19}$. Kim HJ et al, found that the ultrasound method measured shorter ACD measurement as compared to noncontact Biometer ${ }^{20}$. Christoph Tappeiner et al, also reported shorter ACD with ultrasound Biometer with the mean significant difference of $-0.055 \mathrm{~mm}(\mathrm{p}<0.0001)^{16}$. However, $\mathrm{J}$ Santodomingo-Rubido et al, reported the nonsignificant difference in anterior chamber depth $(-0.01$ $\pm 0.08 \mathrm{~mm}, \mathrm{p}=0.24)^{21}$. P J Buckhurst et al, found that the ultrasound biometry measured shorter ACD as compared to PCI LenStar $(0.32 \pm 0.62 \mathrm{~mm})^{22}$.

The mean lens thickness measurement was 4.26 $\mathrm{mm}$ and $4.85 \mathrm{~mm}$ with non-contact and ultrasound technique, respectively. The standard deviation of lens thickness was $0.48 \mathrm{~mm}$ and $0.63 \mathrm{~mm}$ with PCI and ultrasound, respectively. There was a significant difference of $0.59 \pm 0.56 \mathrm{~mm}$ found between both techniques ( $p<0.001$ ). Huseyin Gursoy et al, found similar results in his research $(0.24 \pm 0.28 \mathrm{~mm})$. Kurtz et al. showed that the ultrasound is sensitive to LT changes only if they exceed the measurements that are equivalent to $1.00 \mathrm{D}$, whereas depending on the measured intraocular distance, precision values from 0.3 to $10 \mu \mathrm{m}$ have been reported when using PCI technology. Buckhurst et $\mathrm{al}^{22}$, found similar LT measurements with the non-contact PCI and the US, whereas another report showed a $0.24 \mathrm{~mm}$ lower mean
LT value with the non-contact PCI Biometer ${ }^{23}$. It was seen that the indention in ultrasound technique did not alter the lens thickness as echoes of lens capsule is not affected by corneal indentation. Many possible clarifications for obtaining higher LT with ultrasound can be made; for example, accommodation could be possibly induced more with ultrasound Biometer as both instruments do not have non-accommodative target for fixation. The second possible explanation is the measurement of the off-axis portion of the crystalline lens. Another possible explanation is facing difficulty to always obtain perpendicularity of ultrasound probe, oblique probe may cause thicker lens measurement with ultrasound ${ }^{23}$. This study also found strong negative correlation between ACD and LT. Hasan Hashemi et al, also found the similar results $^{24}$.

Comparison between axial length measured with non-contact and ultrasound technique showed that there was statistically significant difference $(p<0.05)$ between the two. The axial length was recorded larger in non-contact Biometer as compared to contact Biometer (ultrasound) Mean axial length was 23.31 \pm $0.88 \mathrm{~mm}$ and $22.79 \pm 0.92 \mathrm{~mm}$ measured with noncontact and ultrasound technique, respectively. The difference between both techniques was $0.53 \pm$ $0.32 \mathrm{~mm}$. In earlier studies, the precision achieved with PCI was shown to be 10 times better than that of US. The data from our study showed that there was a tendency for hyperopic shift in eyes that undergo PCI biometry. This hyperopic shift may be due to measurement of longer axial length $(0.53 \mathrm{~mm})$ as compared to ultrasound. MS Rajan et al, found that the mean axial length was $23.47 \pm 11 \mathrm{~mm}$ in the PCLI and $23.43 \pm 1.2 \mathrm{~mm}$ in the ultrasound ${ }^{14}$.

Globally, in ophthalmology clinics, the understandable advantage has been seen in utilizing PCI devices in consultation sessions. After installation of non-contact technique, the patients do not need to wait for longer time, there is no need of topical anesthesia with no contamination risk. These improvements will be well received by patients, as hospital visits are often time consuming, and can be costly and inconvenient if unanticipated side effects occur. However, some researchers concluded that optical biometry provided no clinical advantage over conventional applanation ultrasound biometry ${ }^{16}$. Both techniques have their own limitation and advantages over other. Age matched comparison of axial ocular parameters can also improve the results. Repeatability 
of both instruments can also give a rough estimation of more accurate device.

\section{CONCLUSION}

There is a statistically significant difference of axial ocular measurements (CCT, ACD, LT and AL) between the results obtained with contact (ultrasound A-scan) and non-contact (HAAG Streit) biometry. The non-contact Biometer is more preferable as there is no chance of indentation. However, contact Biometer is useful in mature cataract.

\section{Ethical Approval}

The study was approved by the Institutional review board/Ethical review board.

\section{Conflict of Interest}

Authors declared no conflict of interest.

\section{Authors' Designation and Contribution}

Muhammad Arslan Ashraf; Optometrist: Study design, data collection, data analysis, manuscript writing and final review.

Muhammad Suhail Sarwar; Professor of Ophthalmology: Study design and final review.

Muhammad Awais Afzal; Postgraduate Resident: Data collection and final review.

Imran Khalid; Orthoptist: Data collection and final review.

Sehrish Shahid; Optometrist: Data collection and final review.

\section{REFERENCES}

1. Zocher MT, Rozema JJ, Oertel N, Dawczynski J, Wiedemann P, Rauscher FG, et al. Biometry and visual function of a healthy cohort in Leipzig, Germany. BMC Ophthalmol. 2016; 16: 79.

2. Aydin R, Erdur KS, Cabuk SK, Karahan E, Kaynak S. Comparison of Optical Low Coherence Reflectometry Versus Ultrasonic Biometry in High Hypermetropia. Eye Contact Lens, 2018; 44 (12): 1463-1468.

3. Cao X, Hou X, Bao Y. The Ocular Biometry of Adult Cataract Patients on Lifeline Express Hospital EyeTrain in Rural China. J Ophthalmol. 2015; 2015: 171564. Doi:10.1155/2015/171564.

4. Cinar Y, Cingu AK, Sahin M, Sahin A, Yuksel H, Turkcu FM, et al. Comparison of Optical versus
Ultrasonic Biometry in Keratoconic Eyes. J Ophthalmol. 2013; 2013: 481238. https://doi.org/10.1155/2013/481238.

5. Erb-Eigner K, Hirnschall N, Hackl C, Schmidt C, Asbach P, Findl O. Predicting Lens Diameter: Ocular Biometry with High-Resolution MRI. Invest Ophthalmol Vis Sci. 2015; 56 (11): 6847-54.

6. Eleftheriadis H. IOL Master biometry: refractive results of 100 consecutive cases. Br J Ophthalmol. 2003; 87 (8): 960-3.

7. Ribeiro FM, Ferreira FD, Gil LN, Jorge J, Meijome JM. Errors associated with IOL Master biometry as a function of internal ocular dimensions. J Optom. 2014; 7 (2): 75-8.

8. Karabela Y, Eliacik M, Kaya F. Performance of the SRK/T formula using A-Scan ultrasound biometry after phacoemulsification in eyes with short and long axial lengths. BMC Ophthalmol. 2016; 16: 96.

Doi:10.1186/s12886-016-0271-8.

9. Pongsachareonnont $\mathbf{P}$, Tangjanyatam S. Accuracy of axial length measurements obtained by optical biometry and acoustic biometry in rhegmatogenous retinal detachment: a prospective study. Clin Ophthalmol. 2018; 12: 973-80.

10. Wissa AR, Wahba SS, Roshdy MM. Agreement and relationship between ultrasonic and partial coherence interferometry measurements of axial length and anterior chamber depth. Clin Ophthalmol. 2012; 6: 193-8.

11. Németh J, Fekete O, Pesztenlehrer N. Optical and ultrasound measurement of axial length and anterior chamber depth for intraocular lens power calculation. J Cat Refract Surg. 2003; 29 (1): 85-8.

12. Hirnschall N, Varsits $\mathbf{R}$, Doeller B, Findl $\mathbf{O}$. Enhanced Penetration for Axial Length Measurement of Eyes with Dense Cataracts Using Swept Source Optical Coherence Tomography: A Consecutive Observational Study. Ophthalmol Ther. 2018; 7 (1): $119-24$

13. Dong J, Zhang Y, Zhang H, Jia Z, Zhang S, Wang X. Comparison of axial length, anterior chamber depth and intraocular lens power between IOL Master and ultrasound in normal, long and short eyes. PLoS One. 2018; 13 (3): e0194273.

14. Rajan M, Keilhorn I, Bell J. Partial coherence laser interferometry vs. conventional ultrasound biometry in intraocular lens power calculations. Eye (Lond). 2002; 16 (5): 552.

15. Airiani S, Trokel SL, Lee SM, Braunstein RE. Evaluating central corneal thickness measurements with noncontact optical low-coherence reflectometry and contact ultrasound pachymetry. Am J Ophthalmol. 2006; 142 (1): 164-5.

16. Tappeiner C, Rohrer K, Frueh BE, Waelti R, Goldblum D. Clinical comparison of biometry using the non-contact optical low coherence reflectometer 
(Lenstar LS 900) and contact ultrasound Biometer (Tomey AL-3000) in cataract eyes. Br J Ophthalmol. 2010; 94 (5): 666-7.

17. Sallet G. Comparison of optical and ultrasound central corneal pachymetry. Bull Soc Belge Ophtalmol. 2001; 281: 35-38.

18. Much MM, Haigis W. Ultrasound and partial coherence interferometry with measurement of central corneal thickness. J Refract Surg. 2006; 22 (7): 66570.

19. Rohrer K, Frueh BE, Wälti R, Clemetson IA, Tappeiner C, Goldblum D. Comparison and evaluation of ocular biometry using a new noncontact optical low-coherence reflectometer. Ophthalmology, 2009; 116 (11): 2087-92.

20. Kim HJ, Kim HJ, Joo CK. Comparison of IOL Master, A-scan and Orb scan II for measurement of axial length and anterior chamber depth. J Korean Ophthalmol Soc. 2003; 44 (7): 1519-27.
21. Rubido SJ, Mallen E, Gilmartin B, Wolffsohn J. A new non-contact optical device for ocular biometry. $\mathrm{Br}$ J Ophthalmol. 2002; 86 (4): 458-62.

22. Buckhurst PJ, Wolffsohn JS, Shah S, Naroo SA, Davies LN, Berrow EJ. A new optical low coherence reflectometry device for ocular biometry in cataract patients. Br J Ophthalmol. 2009; 93 (7): 949-53. Doi:10.1136/bjo.2008.156554.

23. Gursoy H, Sahin A, Basmak H, Ozer A, Yildirim N, Colak E. Lenstar versus ultrasound for ocular biometry in a pediatric population. Opt Vis Sci. 2011; 88 (8): 912-9.

24. Hashemi H, Khabazkhoob M, Miraftab M, Emamian MH, Shariati M, Abdolahinia T, et al. The distribution of axial length, anterior chamber depth, lens thickness, and vitreous chamber depth in an adult population of Shahroud, Iran. BMC Ophthalmol. 2012; 12: 50. 